\title{
Research Article \\ EFFECT OF PRE-PEELING TREATMENT, PACKAGING AND STORAGE TEMPERATURE ON BIOACTIVE COMPOUNDS AND POST HARVEST LIFE OF MINIMALLY PROCESSED GARLIC CLOVES
}

\author{
MANINDER KAUR ${ }^{1}$, PREETINDER KAUR ${ }^{2}$ AND AMRIT KAUR ${ }^{3}$ \\ 1,2Department of Processing and Food Engineering, Punjab Agricultural University, Ludhiana, Punjab 141004, India \\ 3Department of Mathematics, Statistics and Physics, Punjab Agricultural University, Ludhiana, Punjab 141004, India \\ *Corresponding Author: Email - money.mandy2790@gmail.com
}

Received: May 25, 2018; Revised: June 06, 2018; Accepted: June 07, 2018; Published: June 30, 2018

\begin{abstract}
A study on mechanically peeled garlic cloves was carried out to study the effect of various pre-treatments, coating treatments and storage conditions on the shelf life of peeled cloves. The coated and uncoated samples were stored at ambient and refrigerated conditions $\left(5^{\circ} \mathrm{C}\right)$ and were packed in low density polyethylene (LDPE) of 150 gauges thickness. The qualitative analysis of stored samples was done in terms of total colour difference, ascorbic acid, titrable acidity, pyruvic acid and allicin content. Sensory evaluation was done on the basis of odour rating and visual appearance. The quality of samples was analyzed during storage on regular basis. The study revealed that refrigerated storage helped in better retention of the quality parameters and enhanced the shelf life of both control and hot air treated peeled cloves up to 18 days. Taking into account the non-significant effect of roller speed on peeling efficiency, it was found that physical parameters such as colour, visual appearance, odour and biochemical parameters such as titrable acidity, pyruvic acid and allicin content were best retained for control samples peeled at 300 roller speed stored under refrigerated conditions without any coating treatment.
\end{abstract}

Keywords- Garlic, Pretreatment, Mechanical peeling, Coating, Storage conditions, Physico- chemical parameters

Citation: Maninder Kaur, et al., (2018) Effect of Pre-peeling Treatment, Packaging and Storage Temperature on Bioactive Compounds and Post Harvest Life of Minimally Processed Garlic Cloves. International Journal of Microbiology Research, ISSN: 0975-5276 \& E-ISSN: 0975-9174, Volume 10, Issue 6, pp.-1232-1239.

Copyright: Copyright@2018 Maninder Kaur, et al., This is an open-access article distributed under the terms of the Creative Commons Attribution License, which permits unrestricted use, distribution and reproduction in any medium, provided the original author and source are credited.

\section{Introduction}

Garlic (Allium sativum L.), the spice of human life, is one the most important perennial bulb crops of the lily family (Liliaceae) which is grown all over the plains of India and is used as a condiment throughout the country. India ranks second after China in world's garlic production and contribute $14 \%$ of the world area. The total production of spices in India during 2010-2011 was 5351 thousand million tonnes from an area of 2940 thousand hectares giving productivity of $1.8 \mathrm{MT} / \mathrm{ha}$ [1]. The share of area under garlic is 200.60 thousand hectare with productivity of 53MT/ha. During the same period, Punjab produced 63.5 thousand million tonnes from an area of 18.4 thousand hectares, giving the productivity of $3.5 \mathrm{MT} / \mathrm{ha}$. Punjab ranks first with the highest yield at 14.73 tonnes / ha. Fresh garlic is characterized by its distinct aromatic odour which is seldom carried over into processed garlic [2]. The flavour of garlic is attributed to the sulfur containing volatiles. By the action of an enzyme allinase, allyl -S-cysteine sulfoxide (allin) is converted to diallyl thiosulfinates (allicin) and then disproportionately to disulfides and thiosulfinates. Garlic is valued for its flavor and has an extensive commercial importance because of its wide medicinal value and application in food and pharmaceutical preparations [3]. It has been recognized as a valuable food condiment in everyday cooking. Garlic is commonly processed into dehydrated powder, flakes and slices [4]. This involves a cumbersome unit operation of peeling. With changing lifestyles, people are moving towards readily available processed products. So, the present study was planned to make the garlic cloves conveniently available to the consumers. The peeling was done mechanically on the machine developed in the department. It was found from the literature that surface discoloration, microbial spoilage contributes to loss of shelf life and quality in peeked cloves [5]. There are many studies to control these undesirable changes, such as dipping garlic in hot water treatment to inhibit the root formation [6] or applying high-hydrostatic-pressure treatment combined with organic acids to inhibit browning and reduce microbial count [7]. The major objective of this study was to know the effect of various pretreatments, roller speeds of peeling, coating treatments and storage conditions on the quality attributes of peeled garlic cloves during the storage.

\section{Material and Methods \\ Material}

Fresh harvested garlic cloves were obtained from the local market and were peeled mechanically on the machine developed in the Department of Processing and Food Engineering, Punjab Agricultural University, Ludhiana. The cloves were peeled at control and hot air pretreated conditions and at different roller speed of $300,400,500 \mathrm{rpm}$. Further, half of the peeled cloves were coated with pectin solution (Pectin: water: polyethylene glycol- 3:99:1) and half were left uncoated. These were stored at ambient and refrigerated conditions in LDPE as packaging material. The stored samples were evaluated for various physico- chemical characteristics at regular interval of three days. The parameters observed were total color difference, ascorbic acid, titrable acidity, allicin content, visual appearance and odour characteristics of stored samples.

\section{Total colour difference}

Colour is one of the most important parameters, which is an indicative of the commercial value of the product. The basic purpose was to get an idea of the comparative change in the colour of the fresh, control and pretreated samples. Colour was determined using Hunter lab Miniscan XE Plus Colorimeter [8]. The colour is described by tristimulus value of $L, a, b$ with positive value of $a, b$ indicating red and yellow colour and negative values indicating green and blue colour respectively. 
Value $a, b$ closer to zero indicates grey colour. $L$ indicates the intensity of colour i.e., lightness which varies from $L=100$ for perfect white to $L=0$ for black. For determination of colour, the colorimeter was put on the sample and the values of $L, a, b$ was measured. The colour change was determined using the formula: Color change, $(\Delta E)=\sqrt{ } \Delta \mathrm{L} 2+\Delta \mathrm{a} 2+\Delta \mathrm{b} 2$

Where $\Delta \mathrm{L}, \Delta \mathrm{a}$ and $\Delta \mathrm{b}$ are deviations from $\mathrm{L}$, $\mathrm{a}$ and $\mathrm{b}$ values of fresh sample.

\section{Ascorbic acid}

The ascorbic acid content was determined as per the 2, 6 dichlorophenolindophenol (DIP) method [9]. Accordingly, $5 \mathrm{~g}$ of garlic pulp was prepared by making $100 \mathrm{ml}$ volume with $0.4 \%$ oxalic acid. The mixture was allowed to stand for 10 minutes for uniform mixing. $10 \mathrm{ml}$ of the aliquot was filtered through whatman filter paper in a $250 \mathrm{ml}$ conical flask. The titration was done against $0.04 \% 2,6$ - dichlorophenolindophenol dye to light pink colour. The ascorbic acid was expressed as $100 \mathrm{ml} / \mathrm{g}$ of the sample.

$\mathrm{mg}$ of ascorbic acid $=$ Titre value $\times$ Dye factor $\times$ volume made $\times 100$ Aliquot taken $\times$ weight of sample

\section{Titrable acidity}

Titrable acidity of the stored cloves was estimated by taking $10 \mathrm{mg}$ of the garlic pulp was made to $50 \mathrm{ml}$ volume with distilled water [10]. $10 \mathrm{ml}$ of unfiltered aliquot was titrated against $0.1 \mathrm{~N} \mathrm{NaOH}$ to light pink end point with a drop of phenolphthalein as an indicator. The acidity was calculated as $100 \mathrm{~g} / \mathrm{ml}$ of the sample.

Percent acidity $=$

Titre value $\times$ Normality $\times$ Volume made $\times$ Equivalent weight of acidity of alkali made up Volume of sample $\times$ Volume of aliquot $\times 1000$

\section{Pyruvic acid}

Pyruvic acid content was determined in which garlic cloves were blended with equal volume of water and filtered to obtain $0.5 \mathrm{ml}$ of garlic slurry [11]. To this slurry, $1.5 \mathrm{ml}$ of trichloroacetic acid was added and was covered with paraffin wax for about 1 hour. Later, the mixture was diluted to $20 \mathrm{ml} .1 \mathrm{ml}$ of this solution was added to $1 \mathrm{ml}$ of $0.0125 \% 2,4$ - Dinitrophenylhydrazine and again $1 \mathrm{ml}$ of deionized water was added to each test tube. The test tubes were covered with paraffin wax and placed in water bath at $37^{\circ} \mathrm{C}$ for 10 minutes. At the end, $5 \mathrm{ml}$ of $0.6 \mathrm{~N} \mathrm{NaOH}$ was added to each test tube and \% transmittance was recorded in a spectrophotometer at $420 \mathrm{~nm}$. The pyruvic concentration was calculated using the standard curve for pyruvic acid.

\section{Allicin content}

The allicin content of the garlic slices was determined using a spectrophotometric assay of allicin [12]. It is known that one molecule of allicin reacts with two molecules of cysteine and thud two molecules of S- allyl mercaptocysteine are formed (S-AMC). The unreacted cysteine is quantified using Ellman's reagent (5, 5,- dithio- bis (2- nitrobenzoic acid)(DTNB). In this method, garlic solution was prepared by dissolving one gram of garlic cloves in $30 \mathrm{ml}$ of distilled water. $1 \mathrm{M}$ tris buffer solution of Tris (Hydroxymethyl) aminomethane was prepared. Then, 20 $\mathrm{mM}$ of L-cysteine solution was freshly prepared in this buffer. DTNB solution was made by dissolving $50 \mathrm{mM} \mathrm{NaOAc}$ (sodium acetate) and 2mM DTNB in distilled water. For allicin determination $0.5 \mathrm{ml}$ of $\mathrm{L}$ - cysteine solution was mixed with 0.5 $\mathrm{ml}$ of garlic solution and mixture was incubated at room temperature for 15 minutes (garlic solution). $1.5 \mathrm{ml}$ of this garlic solution was added to $5 \mathrm{ml}$ of DTNB, $10 \mathrm{ml}$ of tris buffer and $83.5 \mathrm{ml}$ of water making volume up to $100 \mathrm{ml}$. Blank sample was prepared by adding $5 \mathrm{ml}$ DTNB,10 $\mathrm{ml}$ Tris and $85 \mathrm{ml}$ distilled water. The amount of 2- nitro-5 thiobenzoate (NTB) was determined by measuring the absorbance of the reaction mixture at $412 \mathrm{~nm}$ in UV quartz cell. The concentration of liberated NTB in samples was calculated from their absorbance at $412 \mathrm{~nm}$, using molar absorption coefficient of 14150 for NTB anion. The amount of NTB $(\mathrm{mM})$ is equal to the concentration of unreacted cysteine in each sample (The concentration of allicin was calculated as below:

Sample absorbance (As) = Total volume /sample volumex total absorbance (At)
Sample concentration (Cs) $=$ As $/ 14150 \mathrm{mM}$

Concentration of unreacted cysteine $=\mathrm{Cs}$

Concentration of cysteine reacted with total thiosulfinates $=20 \mathrm{mM}-\mathrm{Cs} \mathrm{mM}$

Concentration of total thiosulfinates in samples $=\mathrm{Cs} / 2 \mathrm{mM}$

Concentration of allicin $=\mathrm{Cs} / 2 \times 0.7$

\section{Sensory evaluation}

The samples stored at ambient and refrigerated conditions were examined at every three days interval for the purpose of sensory evaluation. The samples were evaluated immediately when opened. A panel was made about the sensory characteristics to be judged. Sensory evaluation rating scales were provided based on which rating was given to various samples. The average values of ratings given were then calculated as per 9 - point hedonic scale [Table-1].

\section{Statistical analysis}

The analysis of effect of process parameters on the storage study of peeled cloves was done using two way ANOVA technique (SAS software) and GraphPad PRISM Version 6 software, Inc. USA. The results of analysis were used to evaluate the significant difference among the various parameters at $p<0.05$. Results and Discussion

\section{Total colour difference (TCD)}

The variation in TCD of different samples during the storage period of mechanically peeled garlic cloves is presented in [Fig-1]. The graphs show the effect of different pre- treatments, coating treatments and roller speed on the TCD values for the samples stored in LDPE of 150 gauges thicknesses at ambient and refrigerated conditions. Statistical analysis of observed data shows a highly significant difference in TCD values for the coated and uncoated samples kept at different storage conditions. The effect of pre-treatment was found to be nonsignificant [Table-2]. TCD was found to be maximum in hot air pretreated and uncoated samples stored at $5^{\circ} \mathrm{C}$ for peeling at $400 \mathrm{rpm}$ whereas it was minimum in control samples stored at $5^{\circ} \mathrm{C}$ and peeled at 300 roller speed without coating.

The effect of roller speed on TCD was statistically analyzed (ANOVA) and was found to be highly significant. With an increase in the roller speed, the TCD increased except for the hot air pretreated coated samples stored at $5^{\circ} \mathrm{C}$. Statistically, it was found that coating treatment was significant during the storage. At $5^{\circ} \mathrm{C}$ i.e., at refrigerated conditions, control coated samples had higher values of TCD than uncoated samples at the different roller speeds. For hot air pretreated samples, the values were lower for the uncoated samples peeled at 300 and 500 roller speeds whereas it was observed to be higher for the same samples at 400 $\mathrm{rpm}$. At the end of storage of 18 days, the minimum value of TCD was found to 3.781 for hot air pretreated uncoated samples peeled at $500 \mathrm{rpm}$ stored at refrigerated conditions and was maximum (24.588) for hot air uncoated samples peeled at $400 \mathrm{rpm}$ of roller speed. The shelf life studies showed that the refrigerated samples stored at $5^{\circ} \mathrm{C}$ were found to be longer acceptable than the samples stored at ambient conditions. The best results were obtained for the control samples without coating stored at $5^{\circ} \mathrm{C}$ and peeled at 300 roller speed.

\section{Ascorbic acid}

The changes in the ascorbic content during the storage period were presented in [Fig-2]. It was found that the pre-treatment and storage period did not significantly affect the ascorbic content of the samples stored in 150 gauges LDPE bags under ambient and refrigerated conditions. The ascorbic acid content decreased with the storage period for all the values of rotational speed at ambient conditions whereas for the samples stored at $5^{\circ} \mathrm{C}$, the value of ascorbic acid content first decreased till 6th day of storage and then slightly increased and at last again showed the decreasing trend. Statistically, it was observed that the rotational speed of the roller had no significant effect on the ascorbic acid [Table-2]. With an increase in roller speed, the values for the ascorbic acid decreased for both ambient and refrigerated conditions even though the drop-in values were not much significant. Considering the different types of pre-treatments and coatings, the combined effect was not found to be significant for both ambient and refrigerated storage conditions. 
Taking into the ambient storage, control uncoated samples exhibited lower ascorbic acid content as compared to coated samples for all the roller speeds. This may be due to the reason that coating prevented the direct contact of air with cloves and higher levels of $\mathrm{O}_{2}$ in the air might have resulted in the greater extent of ascorbic acid depletion. The results reported also showed that pretreatment of peeled cloves exhibit higher ascorbic acid content than the untreated cloves [13]. At $5^{\circ} \mathrm{C}$, control samples with coating had lower values of ascorbic acid than uncoated ones. Similar trend was observed for the hot air pretreated samples. Within the same coating treatment at $5^{\circ} \mathrm{C}$ storage, it was observed that control samples exhibit lower ascorbic acid content. Without coating also, control samples showed lower values of ascorbic acid than hot air pretreated samples. It may be due to the inactivation of enzymes by hot air treatment. The shelf life was estimated on the basis of number of days for which the sample was overall accepted. It was observed that refrigerated samples had prolonged shelf life as compared to control samples.

\section{Titrable acidity}

The effect of different roller speeds, pretreatments, coating treatments and storage conditions on the titrable acidity for the peeled cloves stored in 150 gauges LDPE packages under ambient and refrigerated conditions [Fig-3]. The effect of pretreatments on titrable acidity of samples stored at ambient and refrigerated conditions were observed to be non significant [Table-2]. The variations in the rotational speed of the roller significantly affected the titrable acidity of the samples. With the increase in the rotational speed of the roller, the values of titrable acidity decreased for the samples stored under ambient conditions. For the refrigerated samples also, titrable acidity showed a decreasing trend with an increase in the roller speed. At the end of storage, the values of titrable acidity were found to $8.17 \%, 11.23 \%, 9.10 \%$ and $27.45 \%$ for control coated, control uncoated, hot air coated and hot air uncoated samples stored at $5^{\circ} \mathrm{C}$ and peeled at $300 \mathrm{rpm}$ respectively.

The effect of different pretreatments and coating treatments were observed and was found that coating treatment affected the samples significantly. For the same control conditions, coated samples exhibit significantly lower titrable acidity as compared to uncoated samples for all the roller speeds irrespective of storage condition. For hot air pretreatment, uncoated samples had significantly lower titrable acid content as compared to coated samples for refrigerated conditions. At $5^{\circ} \mathrm{C}$, for the same coating treatment, hot air pretreated samples exhibited higher titrable acid than control samples. It was because of the reason that the temperature of the samples were increased during hot air pretreatment which would have increased the enzymatic reactions resulting in higher titrable acidity than control samples. For uncoated conditions, hot air samples again had higher titrable acidity values as compared to control samples.

The shelf life studies showed that the refrigerated samples had more shelf life as compared to samples stored at ambient conditions. For the control samples, the shelf life is approximately same irrespective of the coating treatment but for hot air pretreated samples, the shelf life of uncoated samples (18 days) was found to be more than that of the coated samples ( 9 days).

\section{Pyruvic acid}

The results for pyruvic acid for the samples stored in 150 gauges thickness LDPE at ambient and refrigerated conditions are presented [Fig-4]. Statistical analysis was done using analysis of variance (ANOVA) [Table-2]. During the storage, the pyruvic acid is degraded for both the ambient and refrigerated conditions of the storage. The maximum value $(0.056 \mu \mathrm{M} / \mathrm{ml})$ was recorded for the control uncoated samples peeled at 500 roller speed and stored at ambient conditions. Slight decrease in the pyruvic acid content was observed with a change in the roller speed. Statistically, it was found that roller speed had significant effect on the pyruvic acid retention. Considering the different coating conditions, for the control sample stored at ambient conditions showed lower pyruvic acid values. At $5^{\circ} \mathrm{C}$ of storage, coated control samples had lower values than uncoated samples. For the hot air treated samples, similar trend was observed where the coated samples had slightly lower values as compared to uncoated samples. It may be due to the reason that coating of samples had prevented the pungency reactions to take place.

During the storage, minimum decrease was found to be in control coated sample stored at $5^{\circ} \mathrm{C}$ and peeled at 300 roller speed. Within the same coating treatment, the results were evaluated for pretreated and control samples. At $5^{\circ} \mathrm{C}$ of storage, taking into account the coating, hot air pretreated samples had lower pyruvic acid content than control ones. Similar trend was observed for the uncoated samples where the hot air treatment exhibited lower pyruvic acid values. The shelf life studies showed that refrigerated samples can be stored for longer period of time as compared to samples placed at ambient conditions.

\section{Allicin content}

The observations for the allicin content were observed for the different roller speeds, pre-treatments, coating treatments and storage conditions are shown in [Fig-5]. Statistically (Table 2), it was found that roller speed had no profound effect on the retention of allicin in the stored garlic. It is observed from the [Fig-5], that allicin content changed very minutely with an increase in the roller speed. Pretreatment, coating treatment did not affect significantly allicin retention. With an increase in the storage period, no dominant effect was observed for any of the parameters and was found to be approximately same for all the varying conditions.

Table-1 Sensory evaluation scale

\begin{tabular}{|c|l|c|}
\hline Scale & \multicolumn{1}{|c|}{ Condition } & Rating \\
\hline $\begin{array}{c}\text { Visual } \\
\text { appearance }\end{array}$ & Very good: No yellowing and browning & 5 \\
\cline { 2 - 3 } & Good: Slight (1-5\%) browning & 4 \\
\cline { 2 - 3 } & Normal : (5-10\% ) browning & 3 \\
\cline { 2 - 3 } & Limited quality : severe ( 10-50\% browning & 2 \\
\cline { 2 - 3 } & Not acceptable : (>51\% ) browning & 1 \\
\hline \multirow{5}{*}{ Odour } & Normal & 10 \\
\cline { 2 - 3 } & Trace off odour & 8 \\
\cline { 2 - 3 } & Slight off odour & 6 \\
\cline { 2 - 3 } & Moderate off odour & 2 \\
\cline { 2 - 3 } & Severe off odour & 0 \\
\cline { 2 - 3 } & Nauseating off odour & \\
\hline
\end{tabular}

\section{Visual appearance}

Visual appearance of the food product is one of the most important quality parameters. The variation in the visual acceptance is presented in [Fig-6]. The evaluation of samples was done on the basis of hedonic scale and scores were given out of 5 points. It was observed that with an increase in the storage period, the acceptability of the samples on the visual basis decreased. The roller speed significantly affected the visual appearance of the samples. The appearance was more acceptable for the samples peeled at 400 roller speed as compared to 500 . It was due to the reason that with an increase in the roller speed, crushing of cloves took place slightly because of abrasive action. Taking into account the effect of coating, it was found statistically highly insignificant for the visual acceptability [Table-2].

For the control samples, it was found that the uncoated samples were visually better than the coated ones and little browning was observed. It was due to the reason that at control conditions, coating may have triggered some biochemical reactions which would had resulted in browning of coated samples. Pretreatment with hot air and refrigerated storage both could have made the coating treatment more stable. With variation in pre- treatment and for the same coating treatment, it was observed that for the coated samples, hot air pretreated samples were found to be in good condition with no browning or slight browning only. For the uncoated samples, similar trend was observed. It was due to the inactivation of deterioration causing enzymes responsible for affecting the visual appearance in terms of browning.

The shelf life studies were carried out and were found that the samples stored at $5^{\circ} \mathrm{C}$ were more acceptable for longer period of days. The best results were reported for samples peeled at 300 roller speed stored at $5^{\circ} \mathrm{C}$ as compared to the samples peeled at other roller speeds. It was because with an increase in the roller speed, the abrasion action became more prominent, thus affected the visual appearance of the peeled samples. 
Effect of Pre-peeling Treatment, Packaging and Storage Temperature on Bioactive Compounds and Post Harvest Life of Minimally Processed Garlic Cloves

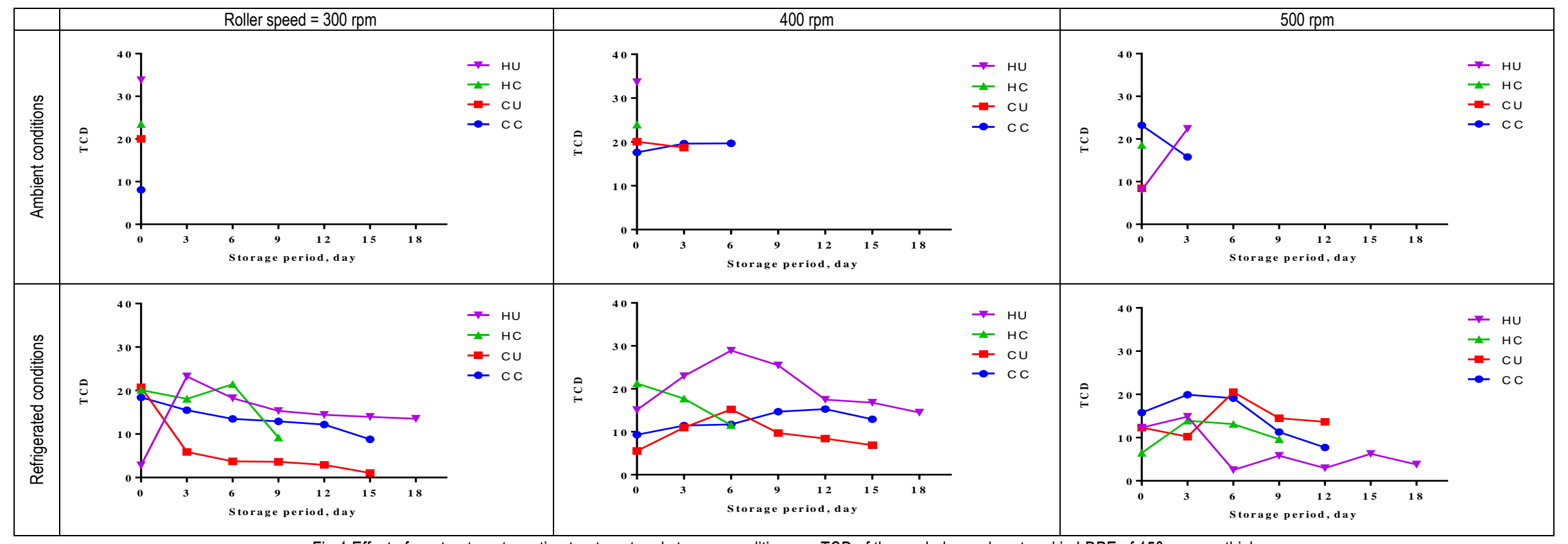

Fig-1 Effect of pre-treatment, coating treatment and storage conditions on TCD of the peeled samples stored in LDPE of 150 gauges thickness

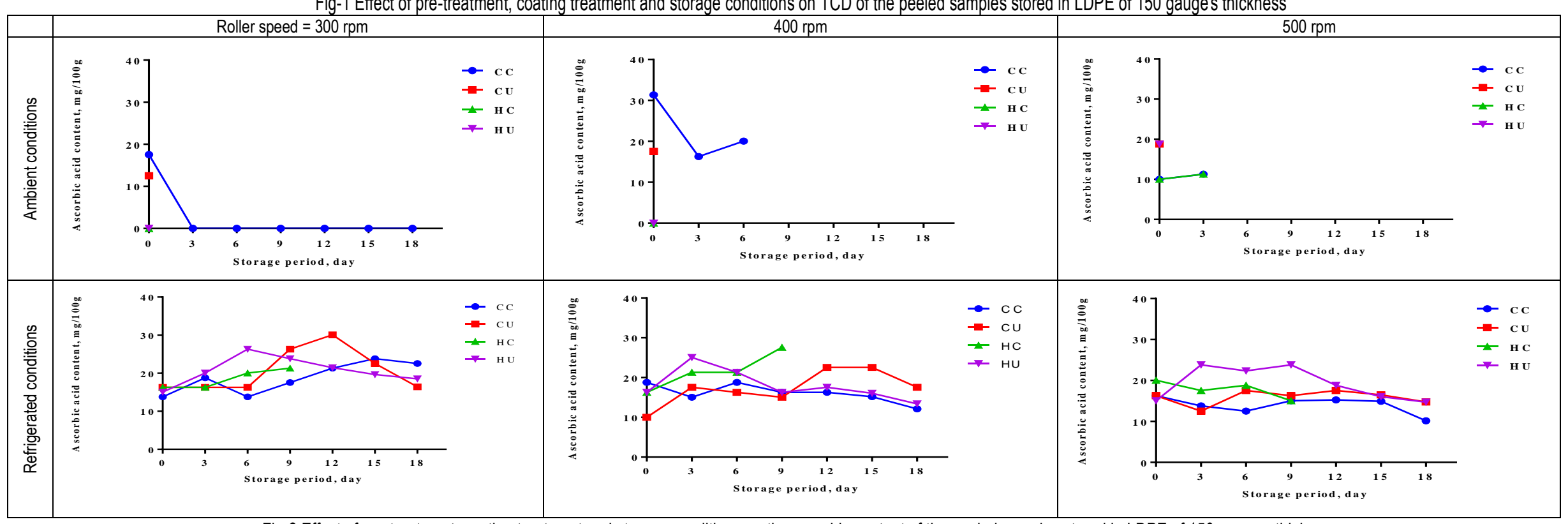

Fig-2 Effect of pre-treatment, coating treatment and storage conditions on the ascorbic content of the peeled samples stored in LDPE of 150 gauges thickness 
Maninder Kaur, Preetinder Kaur and Amrit Kaur

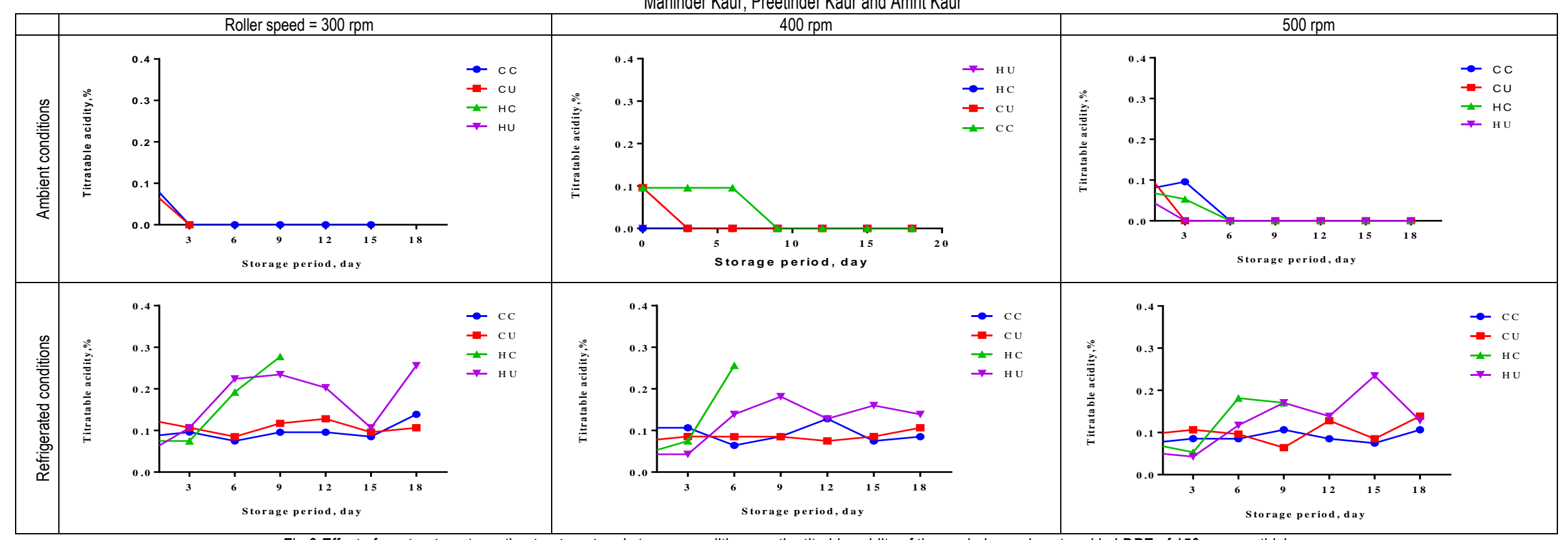

Fig-3 Effect of pre-treatment, coating treatment and storage conditions on the titrable acidity of the peeled samples stored in LDPE of 150 gauges thickness

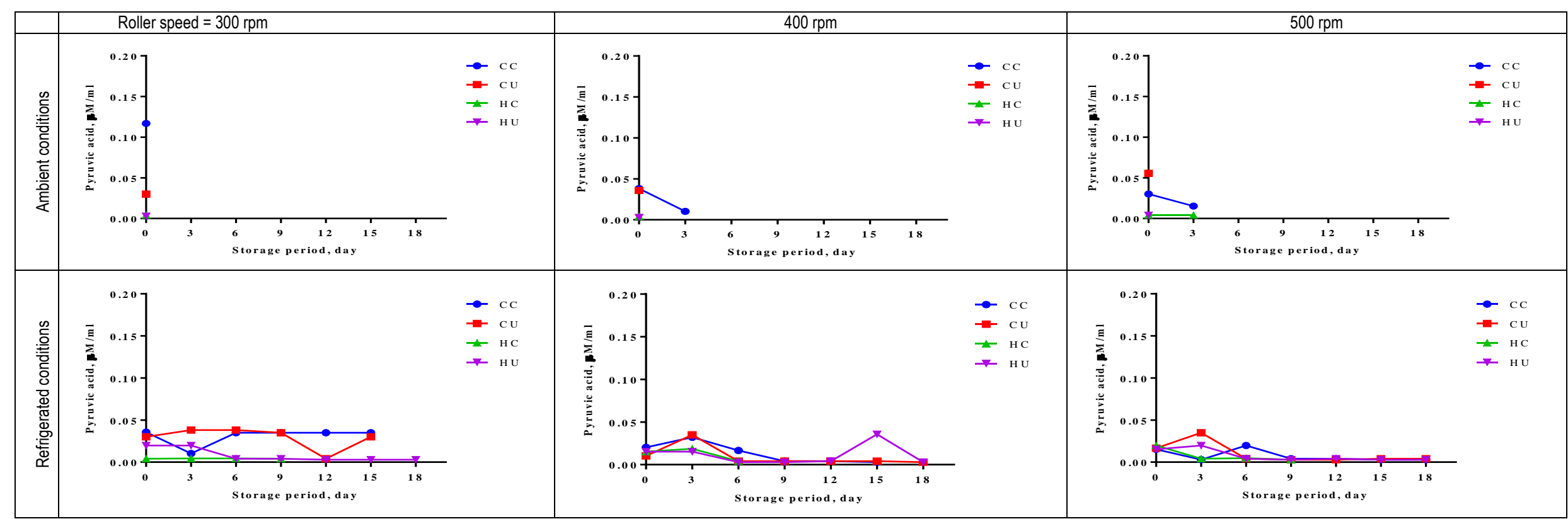

Fig-4 Effect of pre-treatment, coating treatment and storage conditions on the pyruvic acid of the peeled samples stored in LDPE of 150 gauges thickness 
Effect of Pre-peeling Treatment, Packaging and Storage Temperature on Bioactive Compounds and Post Harvest Life of Minimally Processed Garlic Cloves

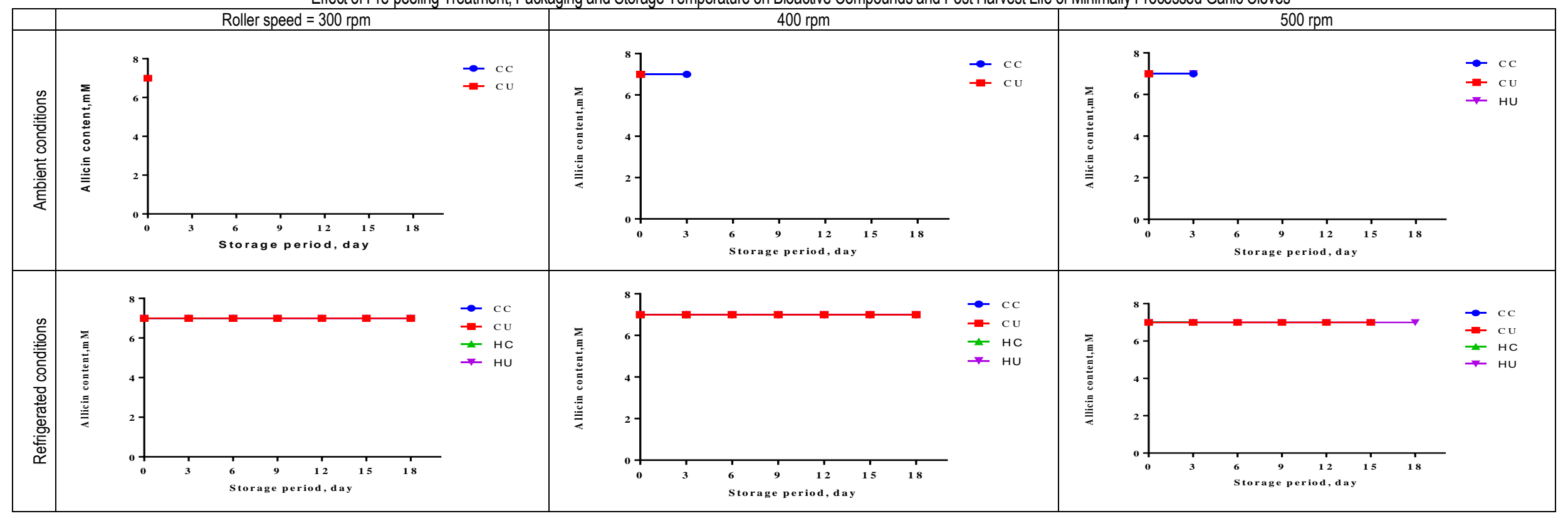

Fig-5 Effect of pre-treatment, coating treatment and storage conditions on the allicin content of the peeled samples stored in LDPE of 150 gauges thickness

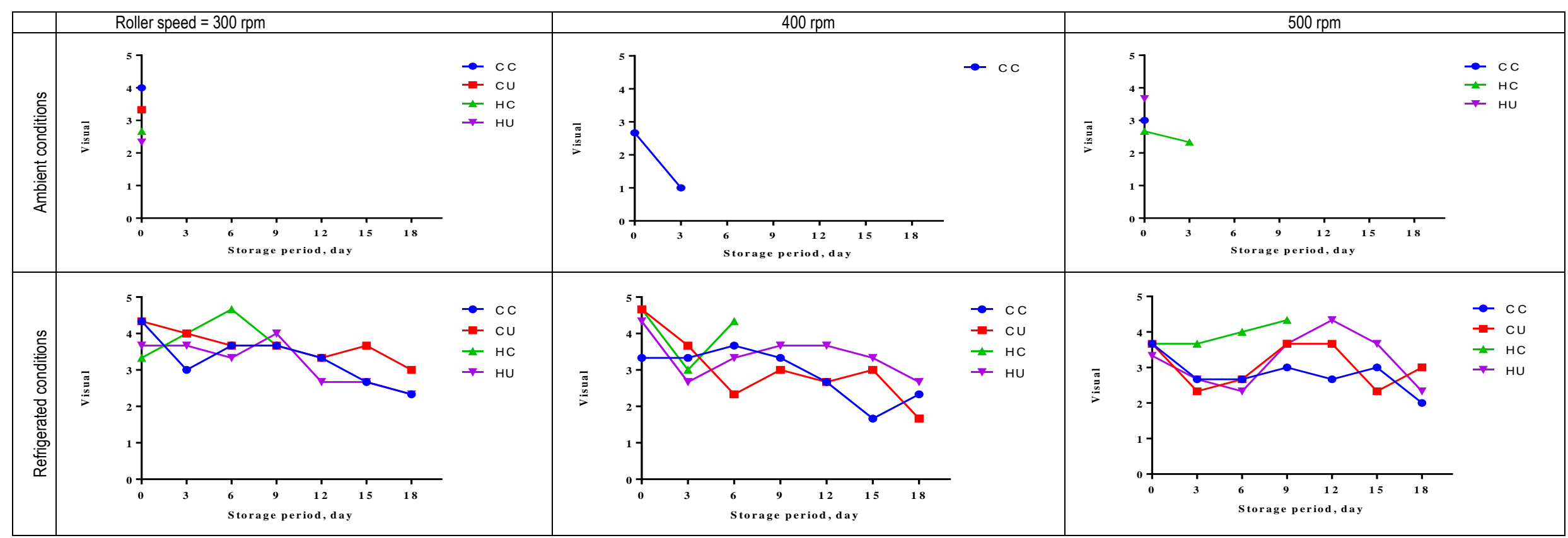

Fig- 6 Effect of pre-treatment, coating treatment and storage conditions on visual appearance of the peeled samples stored in LDPE of 150 gauges thickness 
Maninder Kaur, Preetinder Kaur and Amrit Kaur

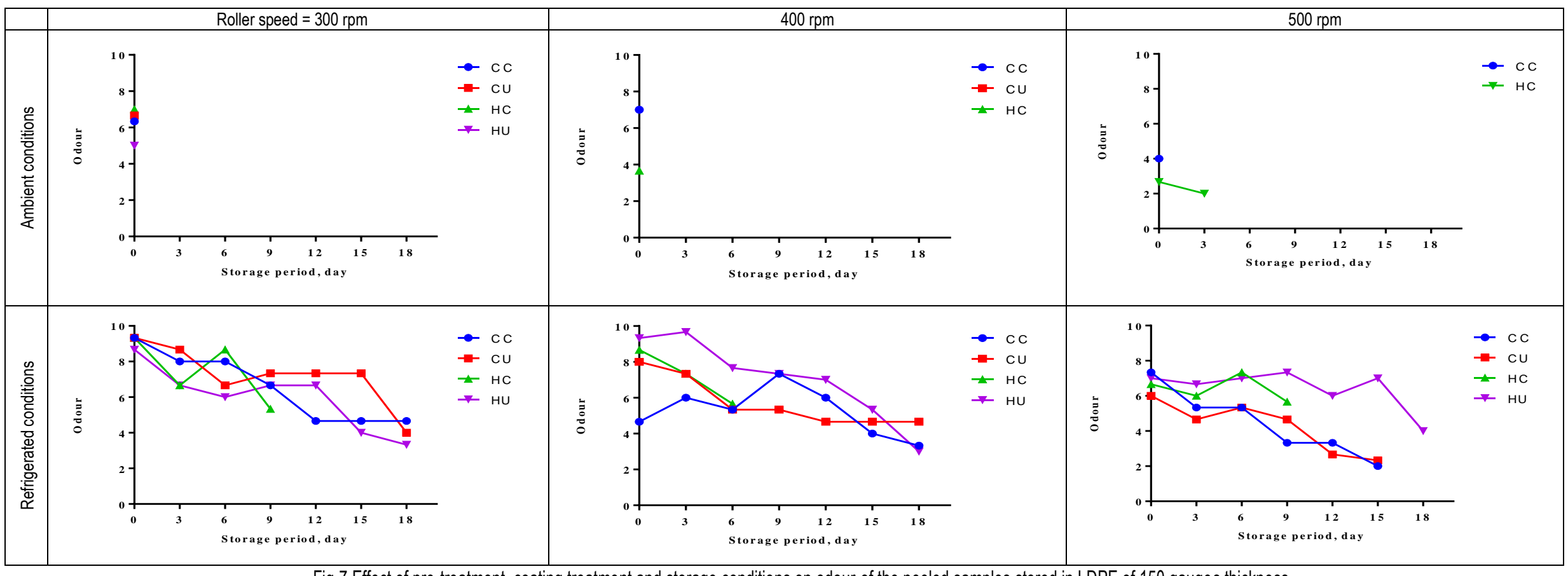

Fig-7 Effect of pre-treatment, coating treatment and storage conditions on odour of the peeled samples stored in LDPE of 150 gauges thickness

Table-2 ANOVA for different quality parameters observed during the storage of peeled cloves under different storage conditions

\begin{tabular}{|c|c|c|c|c|c|c|c|}
\hline Quality parameter & $\begin{array}{l}\text { Total colour } \\
\text { difference }\end{array}$ & Ascorbic acid & Titrable acidity & Pyruvic acid & Allicin content & Odour characteristics & Visual appearance \\
\hline Pretreatment & 0.9150 & $<.0001$ & 0.1151 & $<.0001$ & $<.0001$ & 0.0003 & 0.0003 \\
\hline Storage Period & $<.0001$ & $<.0001$ & $<.0001$ & $<.0001$ & $<.0001$ & $<.0001$ & $<.0001$ \\
\hline RPM & $<.0001$ & 0.8576 & 0.0161 & $<.0001$ & 0.3124 & 0.0014 & 0.2039 \\
\hline Coating treatment & 0.0737 & $<.0001$ & $<.0001$ & 0.8936 & $<.0001$ & 0.0003 & $<.0001$ \\
\hline Storage condition & $<.0001$ & $<.0001$ & $<.0001$ & $<.0001$ & $<.0001$ & $<.0001$ & $<.0001$ \\
\hline Pretreatment*Storage Period & 0.0025 & $<.0001$ & $<.0001$ & $<.0001$ & 0.5680 & 0.0166 & 0.0001 \\
\hline Pretreatment*RPM & $<.0001$ & 0.0002 & 0.0155 & $<.0001$ & 0.0048 & 0.0021 & 0.0188 \\
\hline Pretreatment ${ }^{\star}$ Coating treatment & $<.0001$ & $<.0001$ & $<.0001$ & 0.0102 & $<.0001$ & $<.0001$ & $<.0001$ \\
\hline Pretreatment*Storage condition & 0.8592 & 0.2938 & $<.0001$ & 0.3595 & 0.0006 & 0.0027 & 0.0005 \\
\hline Pretreatment*Storage periodRPM & 0.0098 & 0.0281 & 0.0054 & 0.0006 & 0.1171 & 0.1579 & 0.0409 \\
\hline Pretreatment*Storage Period ${ }^{*}$ Coating & 0.0196 & $<.0001$ & $<.0001$ & 0.0699 & $<.0001$ & $<.0001$ & 0.0001 \\
\hline Pretreatment*Storage Period*Storage condition & $<.0001$ & $<.0001$ & $<.0001$ & $<.0001$ & $<.0001$ & 0.0059 & $<.0001$ \\
\hline StoragePeriod ${ }^{*} \mathrm{RPM}^{*}$ Coating treatment & 0.7447 & 0.2878 & 0.0014 & 0.0010 & $<.0001$ & 0.7125 & 0.1811 \\
\hline StoragePeriod*RPMStorage condition & 0.0050 & 0.3539 & 0.0085 & 0.0063 & 0.0008 & $<.0001$ & $<.0001$ \\
\hline RPM $^{*}$ Coating ${ }^{*}$ Storage condition & $<.0001$ & $<.0001$ & $<.0001$ & 0.0274 & $<.0001$ & $<.0001$ & $<.0001$ \\
\hline
\end{tabular}




\section{Odour}

The change in the odour of the stored samples is presented in [Fig-7]. An analysis of variance (ANOVA) value for the odour were performed and is presented in [Table-2]. The sensory evaluation on the basis of odour was found out of 10 points hedonic scale. The effect of various pre-treatments, coating treatments and storage period was studied on the odour of samples stored in 150 gauges LDPE under ambient and refrigerated conditions. As the storage period increased, the development of off odour started to begin. Hot air coated samples stored at ambient conditions showed the minimum value of scores. The roller speed had significant effect on the odour of the stored samples. With an increase in the roller speed, the score values found to decrease. The coating treatment also significantly affected the odour characteristics when analyzed statistically. For the control samples stored at $5^{\circ} \mathrm{C}$, the coated samples had developed more off odour as compared to uncoated samples. It may be due to the reason that some enzymatic reactions took place between the coating and LDPE package.

Similar effect was observed for hot air pretreated samples in which the uncoated samples had higher score near to the normal value of acceptability as compared to coated samples. The maximum score was observed for hot air pretreated sample without coating which was stored at $5^{\circ} \mathrm{C}$ and peeled at 400 roller speed. Comparing the effect of pre-treatment, for uncoated conditions, hot air pretreated samples was found to have sores near to the normal values as per the hedonic scale. It may be due to the reason that hot air pretreatment might have inactivated the microorganisms responsible for the deterioration of the quality of the samples. For the coating treatment, hot air pretreated samples found to be more acceptable taking into account the odour characteristics. The shelf life was estimated from the plots of odour with the storage period and it was found that the refrigerated samples were more stable as compared to ambient conditions. Hot air pretreated coated samples were found to be most unstable. The best results were obtained for the control uncoated samples at 300 roller speed with all types of pretreatments, coating treatments as compared to other samples.

\section{Conclusion}

The study shows that the refrigerated storage helped in better retention of the quality parameters and enhanced the shelf life of both control and hot air treated peeled cloves up to 18 days. Taking into account the non significant effect of roller speed on peeling efficiency, it was found that physical parameters such as colour, visual appearance, odour and biochemical parameters such as titrable acidity, pyruvic acid and allicin content were best retained for control samples peeled at 300 roller speed stored under refrigerated conditions without any coating treatment.

Application of research: The various post harvest preservation techniques and quality testing methods which are required to produce a garlic product with a flavor profile as close to fresh garlic. Further the value addition through packaging and storage will be instrumental in substantially expanding the export basket of garlic and its derivative products.

Research Category: Post harvest preservation techniques
*Research Guide or Chairperson of research: Dr. Preetinder Kaur University: Punjab Agricultural University, Ludhiana, Punjab 141004, India Research project name or number: M Tech. Thesis

\section{Author Contributions: All author equally contributed}

Author statement: All authors read, reviewed, agree and approved the final manuscript

\section{Conflict of Interest: None declared}

Ethical approval: This article does not contain any studies with human participants or animals performed by any of the authors.

\section{References}

[1] Anonymous (2011) National Horticulture Board data base

[2] Pezutti A. and Crapsite G.H. (1997) J Food Engg., 31,113-23.

[3] Sharma G.P., Prasad S. (2001) J Food Engg., 50, $99-05$.

[4] Ahmad J.I. (1996) Nutr Food Sci., 96(1), 32-35.

[5] Kang J. and Leedong S. (1999) J Fd. Sci and Biotechnol., 8(1),68.

[6] Cantwell M.I., Kang J. and Hong G. (2003) Postharvest Biol Technol. 30,57-65.

[7] Hong G.H., Jang H.S. and Kim V.B. (2001) Han' guk wonye Hakhoechi, 40 (1), 19-22.

[8] Hunter S. (1975) The measurement of appearance, John Wiley and Sons, New York, 304-05.

[9] Anonymous (2006) Official methods of Analysis of the Association of Official Analytical Chemists (accessed on 10 March, 2014).

[10] Ranganna S. (1986) Handbook of analysis and quality control for fruits and vegetable products. $2^{\text {nd }}$ edition, Pp 171-74. Tata McGraw Hill publishing company Ltd. New Delhi, India.

[11] Ketter. C.A.T and Randle, W.M. (1998) Proc $19^{\text {th }}$ Workshop Conf ABLE, University of Georgia, Georgia, 19, 177-96.

[12] Han J., Lawson L., Han G. and Han P. (1995) Analytical Biochemistry, 225, 157.

[13] Donachari M., Venkatachalapathy K. and Rajeshkarppa K.S. (2010) J Dairy Fds Home Sci., 29 (2),130-35.

[14] Singh P., Singh S. and Singh B.R. (2014) Int J Food Engg Technol., 2 (7), 141-56.

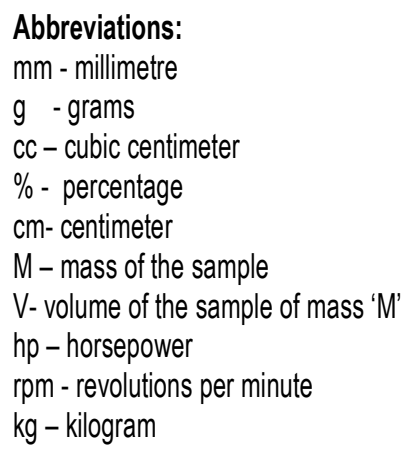

Acknowledgement / Funding: Author thankful to Punjab Agricultural University, Ludhiana, Punjab 141004, India 